ConNotas. Revista de Crítica y teoría literarias / Vol. VI, Núm. 10 / 2008

\title{
La paradoja como principio constructivo en los relatos policial y fantástico de Jorge Luis Borges
}

\author{
José Miguel Candelario Martínez
}

\section{Resumen:}

La paradoja es explicada como un constructo que subvierte la lógica de la razón y, por lo tanto, contiene en sí una crítica al sentido estable que el hombre cree ver en la "realidad". Las paradojas pueden entenderse como análogas a la literatura en que dan cuenta de problemas existenciales, ontológicos o metafísicos. Para Borges, la paradoja revela una realidad terrible y, por lo tanto se traduce en sus relatos en una insistencia en la posibilidad de la existencia de lo fantástico. Además, la paradoja se presenta como elemento constructivo de sus relatos policiacos donde ésta se traduce en términos de un enigma que debe ser resuelto mediante el pensamiento deductivo. El interés de Borges por la paradoja lo ubica entre el grupo de pensadores que a través de los siglos han buscado expresar y dar sentido a los fenómenos que aterran a la humanidad.

Palabras clave:

Jorge Luis Borges, Paradoja, relato fantásito, relato policiaco, Zenon de Elea.

Es común hablar de Jorge Luis Borges y la argumentación paradójica que tanto le fascinó partiendo de Zenón de Elea y sus afirmaciones sobre la imposibilidad del movimiento. El mismo Borges retoma estos argumentos como los inicios de dicho problema lógico en

\footnotetext{
${ }^{*}$ Universidad de Sonora.
} 
occidente en su inconclusa Biografía del infinito que refiere en el ensayo titulado "Avatares de la tortuga" en alusión al dilema que representa la carrera de este reptil contra el héroe de breve vida y pies ligeros de la mitología clásica.

Zenón es considerado el máximo exponente de estos sofismas. Antes que éste, no obstante, se tienen noticias de las interrogantes de Anaximandro que a la manera del huevo y la gallina pretendía esclarecer el origen de los hombres o del universo, afirmando que todas las cosas tienen un principio y sosteniendo, al mismo tiempo, que una de ellas no lo tiene. $Y$ es que el concepto mismo que se empeñó en esclarecer no tenía asideros consistentes, era complicado e inabarcable por lo que su explicación, cualquiera que le diera, resultaría paradójica. Dice sobre esto Roy Sorensen su Breve historia de la paradoja: "Nos sentimos inseguros ante toda suerte de indeterminación: infinitud, vaguedad, azar. Estos son conceptos particularmente propensos a la paradoja" (25). Anaximandro fue el primero en intentar esclarecer el origen del origen, por ello es el precursor de la paradoja, cualquiera que se lo hubiera propuesto, sin embargo, lo habría sido.

Zenón, por otro lado, es quien ha sido objeto de más estudio y reconocimiento, tal vez porque sus proposiciones paradójicas tenían la voluntad de serlo.

El planteamiento base de este filósofo es el siguiente: el movimiento es imposible porque para que un objeto en movimiento avance una determinada distancia, antes debe avanzar la mitad de ésta y antes la mitad de ésta, así hasta el infinito, de modo que en realidad no avanza en lo absoluto.

Este tipo de argumentos se halla dentro de los teoremas que parecen extraordinarios e imposibles pero que, por ser lógicamente inatacables, son aceptados como verdaderos aunque trasciendan la imaginación, la intuición y sobre todo, el sentido común. Muchas paradojas, tras ser analizadas detenidamente, resultan estar fundamentadas sobre premisas falsas o inconclusas, de modo que en realidad son consideradas artilugios retóricos carentes de validez por el defecto mencionado; hay otras, sin embargo, las más desconcertantes, que aún sobre premisas verdaderas llegan a conclusiones 
que sólo son posibles en el mundo de la imaginación. Otras paradojas, las matemáticas, por ejemplo, han ayudado a la evolución de esta ciencia planteando problemas a los estudiosos que buscan la manera de llenar vacíos y solventar carencias. Todas, no obstante, llaman nuestra atención por su aterradora manera de poner en entredicho conceptos fundamentales del saber humano.

En el curso de su estudio, la paradoja se ha asociado también con la ironía, y la ironía nos lleva directamente a una visión crítica de los cánones, instituciones y aun de la realidad. La asociación puede parecer natural considerando que el enfoque originario de la paradoja no era serio, sino que pretendía desarrollar pequeñas argucias que representaran un reto para los sofistas avezados en retórica. Zenón pretendía negar fenómenos cuya existencia tomaba por verdadera únicamente como constructo argumentativo que destacase sus facultades de sofista, lo que no quiere decir que en realidad creyera que el movimiento es imposible o que no ocurre.

La paradoja se caracteriza por poseer, al mismo tiempo, un carácter falso y otro verdadero. Afirmar que la paradoja incluye, simultáneamente las nociones de verdad y de falsedad o error es, en sí, una paradoja, pero ello no descalifica la posibilidad de que esto ocurra. La realidad misma plantea cotidianamente ese tipo de posibilidades y es esto lo que fascina a Borges; encontrar un sistema de afirmación lógica que cumpla con la función de posibilidad-imposibilidad, lo mismo que en el mundo los fenómenos fantásticos inexplicables que el autor tanto explotó, fue para éste, más que una señal, una manera de comprobar a través del método, que el mundo no es todo lo que vemos y que hay en el universo misterios inexplicables y aun sobrenaturales que jamás tendrán una explicación racional convincente. De algún modo, Borges pretende homenajear con esto la duda inherente a los hombres, el cuestionamiento razonado que da origen al conocimiento, de ahí que dedica muchas de sus páginas más valiosas a alabar el desconcierto que generan estas construcciones lógicas conocidas como paradojas.

Los diccionarios de retórica definen la paradoja como la unión de ideas opuestas y como el carácter ilógico de un argumento aparentemente lógico. Leemos en el diccionario de Beristáin, por ejemplo: 
Paradoja (o antilogia o endiasis). [es la] Figura de pensamiento que altera la lógica de la expresión pues aproxima dos ideas opuestas y en apariencia irreconciliables, que manifestarían un absurdo si se tomaran al pie de la letra; razón por la que los franceses suelen describirla como "opinión contraria a la opinión”- pero que contienen una profunda y sorprendente coherencia en su sentido figurado. (v. Paradoja)

No es sólo el sentido figurado el que parece coherente en una paradoja y no es únicamente la oposición de ideas lo que desarrolla. La maravilla de esta forma argumentativa consiste en afirmar algo en apariencia incontrovertible de manera lógica y sintácticamente correcta de modo que no pueda ser calificada de falacia.

La paradoja demuestra la excepción de las reglas, la fragilidad de los entramados lógicos y epistemológicos que el hombre tiene como verdaderos; la posible falsedad del mundo. Dice Sabine Lang sobre la naturaleza de ésta:

La lógica sólo puede darse cuenta de que ciertas afirmaciones, a cuya verdad no quisiera renunciar, caen en contradicción con otras afirmaciones, cuya verdad le parece igualmente imprescindible. Pero, según el principio de contradicción, regla primordial del conocimiento, no puede ser verdadero lo que se contradice a sí mismo. Por consiguiente, la lógica concibe la paradoja como un punto ciego de la observación, en el que el principio de ambivalencia, que dice que toda afirmación es necesariamente o cierta o falsa, está sin vigencia, llegando a percibirse al mismo tiempo tanto una como otra de las afirmaciones que se excluyen mutuamente. (21)

Nótese este interesante contrasentido, tanto una como la otra, esto es, tanto la verdad como la falsedad simultáneamente. Recurso o posibilidad que ayuda al pensamiento a dar sentido a aquello que, por naturaleza, no lo tiene. Pero el sentido a que se llega con estas conclusiones no deja conforme al pensador. El individuo que topa frente a estos enormes abismos sufre una conmoción al con- 
templar las certezas desmoronarse. Este estremecimiento, esta insatisfacción curiosa es lo que Jorge Luis Borges provoca en el lector al emplear la paradoja como sustento de sus narraciones.

$\mathrm{Y}$ es que parece que la literatura es el terreno ideal para el desarrollo de estos sofismas, ya que en ésta las paradojas adquieren el carácter de ejemplo al afectar anécdotas, personajes y situaciones que, como es correlativo a las letras, dan cuenta de la naturaleza y espíritu de los hombres planteando problemas existenciales, ontológicos y metafísicos.

Las paradojas son generalmente "resueltas" o explicadas con la noción de infinito, de ahí que hayan ocupado la atención del cuentista argentino poderosamente. No sólo dedica algunos de sus ensayos a rastrear sus orígenes e implicaciones metafísicas y poéticas ${ }^{1}$ sino que trata también de reproducir su forma discursiva, su estructura argumental, a la hora de hacer literatura.

Borges ve en la paradoja el planteamiento que da en un punto clave al exhibir el sinsentido del mundo, la fragilidad de la supuesta realidad. Leemos, más como mortificación que como cuestionamiento retórico, las líneas finales de los "Avatares de la tortuga":

El mayor hechicero - escribe memorablemente Novalis- sería el que se hechizara hasta el punto de tomar sus propias fantasmagorías por apariciones autónomas. ¿No sería ése nuestro caso? Yo conjeturo que así es. Nosotros (la indivisa divinidad que opera en nosotros) hemos soñado el mundo. Lo hemos soñado resistente, misterioso, visible, ubicuo en el espacio y firme en el tiempo; pero hemos consentido en su arquitectura tenues y eternos intersticios de sinrazón para saber que es falso. (Ficcionario 143)

${ }^{1}$ Véase por ejemplo los ensayos "Avatares de la tortuga" (1939), "Kafka y sus precursores" (1951), "Nueva refutación del tiempo" (1947), "La esfera de Pascal" (1951), "De alguien a nadie" (1950), entre otros, donde el autor reflexiona sobre estos problemas lógicos que de algún modo prefiguran una preocupación filosófica constante. 
Esos intersticios, esas fisuras, además de poder ser intuidas pueden ser expresadas a través de las paradojas, mismas que revelan, en su inverosimilitud absurda, una realidad terrible, la de la falsedad de lo cognoscible a través de la razón.

Además el formato en que se presentan las paradojas logra ser por sí mismo atractivo; hay algo de placer incómodo en cada una de ellas. Dice Barrenechea tratando de entender la fascinación que en Borges se suscitaba ante los famosos sofismas:

Ante la paradoja de Aquiles y la tortuga siente el mismo estremecimiento por el misterio que se entrevé y el placer estético por la Belleza de la formulación; y halla esa belleza en la metáfora que Zenón de Elea acuñó, por la aventura que promete y que él desenvuelve imaginativamente en una perpetua persecución de seres que disminuyen o se agrandan monstruosamente. [...] Pero también encuentra el mismo valor estético en las límpidas formulaciones matemáticas. (36)

A propósito de las implicaciones ideológicas que puede tener la inclusión recurrente de la paradoja en los relatos borgeanos, Víctor Bravo en su estudio sobre Borges titulado El orden y la paradoja señala esta característica como un reflejo del pensamiento de la modernidad. En dicho trabajo afirma:

Una pregunta empieza a articularse con la modernidad (y quizás aún más remotamente, con el nacimiento del logos, en la Grecia de hace más de 27 siglos) y que finalmente se pronuncia con toda claridad en la física cuántica: ¿existe el mundo?; pregunta, quizás, la más banal y la más compleja. Desde esa conciencia fundamental, la época moderna ha desarrollado sus historias, sus sueños y sus pesadillas, ha desplegado el más amplio programa optimista y se ha dado de tope con las aristas y muros del absurdo y del escepticismo. (18-19)

Visto de este modo, dicha interrogante subyace, latente, en el inconsciente de los grupos humanos de todos los tiempos. La modernidad no la monopoliza, y la física cuántica no es la primera en 
toparse con pared a la hora de querer esclarecerla. Borges la percibe en las paradojas de Zenón, en la sofística en general ${ }^{2}$ y no sólo en Berkeley, Schopenhauer, y la filosofía moderna. Dichos cuestionamientos aparecen desde la antigüedad hasta nuestros días lo que nos lleva a concluir que éstos han existido desde entonces como una constante del pensamiento humano; no ha habido un siglo en que la duda haya estado del todo ausente. No obstante, ha habido periodos de la historia donde la mencionada duda ha sido el eje fundamental del comportamiento intelectual y estético de los hombres (la modernidad señalada por Bravo) y que en ellos ha habido autores (como Borges) que buscan demostrar que la duda es inherente al hombre porque algo nos dice de nosotros y del mundo y que el universo mismo se encarga de sembrar dichas interrogantes. Dice a este respecto Sabine Lang:

Desde el punto de vista de la historia literaria, la narración paradójica se manifiesta muy a menudo en las épocas de crisis estéticas o, aún más, en tiempos de replanteamientos poetológicos, como por ejemplo en la Antigüedad tardía, la Alta Edad Media, el Renacimiento tardío y el Barroco, la Ilustración tardía, el Romanticismo tardío, la Modernidad y la Postmodernidad. (25)

En Borges, pues, parece renacer con nuevos bríos una conciencia latente en el ser humano que, algunas veces con más fuerza otras con menos, se manifiesta en la elaboración de preguntas y en la manifestación de dudas.

Con estos cuestionamientos, con estas dudas, Borges no pretende solamente dar mortificaciones a los lectores de sus cuentos, hay en la inserción de la paradoja a la narrativa, una intención estética.

\footnotetext{
${ }^{2}$ El sofista Gorgias (480-380 a. C. aprox.) afirmó en sus tratados tres premisas fundamentales: Nada existe; si algo existe no puede ser conocido; si algo es conocido no puede ser comunicado. Dio el título a uno de los diálogos de Platón donde se critican sus ideas.
} 
Para Borges todo aquello que está un nivel más allá de lo real es fantástico. Una disciplina que trate sobre conceptos y problemas trascendentales como es la metafísica, se le antojaba otra rama de la literatura fantástica. Así que, bajo este supuesto, el doble, la posible falsedad de la existencia, la circularidad del tiempo o su infinita repetición son, para el autor argentino, equivalentes a un fantasma o a un monstruo. Si la inclusión de un humanoide que chupa la sangre puede generar múltiples tramas dignas de ser llevadas al cuento o a la novela, imaginemos lo que sucedería con un punto donde caben todos los tiempos y todos los espacios, o con un individuo que ha descubierto lo absurdo de una vida mortal o con otro que se descubre a sí mismo a distinta edad a las orillas de un río que es dos ríos. Para Borges no hay diferencia, todo es ficcionalizable, inclusive los gigantescos problemas filosóficos que atormentaron y atormentan a los grandes pensadores.

Para crear narraciones fantásticas la paradoja es materia idónea, pero también lo es para el desarrollo del relato de tipo policiaco. En este último funciona como sembrador de enigmas que han de ser resueltos por medio del razonamiento deductivo, una vez más, con los elementos propios de la lógica exhibiendo los tropiezos y debilidades de la misma.

A la intención estética se suma también, como intención literaria, el de la crítica. Borges se auxilia de planteamientos fácilmente reconocibles, lugares comunes de los distintos filósofos que cita, para otorgarse, con ellos como sustento, credibilidad. Sus cuentos están cimentados sobre supuestos y teorías desarrolladas por investigadores con rigor científico y son incluidas en los relatos para que el lector no sienta que son meras ocurrencias descabelladas, para que piense que hay algo de verdad en lo que se cuenta. Dice a este respecto Ingrid Simson: "En la mayoría de estos cuentos-ensayos aparece un yo narrador que ofrece informaciones científicas, pero que en el trascurso del cuento se contradice y se revela ante el lector como un narrador poco creíble" (111).

Porque ¿qué resulta más aterrador, que nos digan que un ser monstruoso con escamas y tentáculos hace destrozos en una galaxia lejana o que dicho monstruo anda suelto por nuestro vecinda- 
rio? Los elementos de veracidad que nuestro vecindario le otorgaría a la historia del monstruo sin duda ayudaría a provocar un efecto mucho más significativo, una conmoción mayor; por ello, en Borges la veracidad se busca constantemente, aunque esa verdad, por la naturaleza de la ficción, por la naturaleza de la ficción fantástica, esté planteada a medias, a través de una paradoja. Por este motivo tampoco es gratuito que cosas fantásticas y lógicamente monstruosas ocurran en un Buenos Aires geográficamente localizable. Todo esto además comulga con la finalidad fundamental de la lógica formal, que es validar el razonamiento; por ello lo fantástico-paradójico está justificado sistemáticamente, para hacerlo, si no verdadero, argumentalmente coherente consigo mismo.

Borges pues, critica el pensamiento moderno desde el pensamiento moderno, no al margen. Exhibe las deficiencias de éste como defectos derivados del pensar humano. El autor sabe que desde muy temprano, el hombre se dio a elaborar teorías y conceptos que no eran propios de una naturaleza imperfecta y finita. Conceptos como eternidad, infinito o perfección representan, en la imaginación de los mortales, que no nacieron para tan altos vuelos, una imposibilidad, una paradoja. Sobre este punto dice Roy Sorensen: "Las paradojas señalan las fallas en nuestro mundo del sentido común" (14). O en palabras de Simson: "influido por los procedimientos de Franz Kafka y Paul Valéry, Borges se propone mostrar a los lectores los límites de nuestro pensamiento racional, que, como hemos visto antes, es uno de los objetivos de la paradoja" (110).

De este mismo modo, Borges comunica, sigue comunicando, los grandes problemas expuestos por filósofos y pensadores; fenómenos y prodigios lógicos que aterran por resultar inconcebibles son su más grande preocupación ya que enunciar estos y reconocer lo imposible de su resolución nos sitúa en un mundo donde reina la fantasía y abundan los enigmas. 


\section{Bibliografía}

Barrenechea, Ana María. La expresión de la irrealidad en la obra de Borges y otros ensayos. México: El Colegio de México, 2000.

Beristáin, Helena. Diccionario de retórica y poética. $8^{\text {a }}$. ed., México: Porrúa, 2003.

Borges, Jorge Luis. Ficcionario. Comp. Emir Rodríguez Monegal. México: Fondo de Cultura Económica, 1997.

Bravo, Víctor. El orden y la paradoja. Venezuela: Universidad de los Andes, 2003.

Lang, Sabine et al. La narración paradójica. Madrid: Iberoamericana, 2006.

Simson, Ingrid. "El principio de la paradoja en la literatura latinoamericana: de Jorge Luis Borges a Jorge Volpi", Sabine Lang, et al. La narración paradójica, 107-19.

Sorensen, Roy. Breve Historia de la paradoja. Barcelona: Tusquets, 2007. 